\title{
Information systems effectiveness and organisational culture: an underlying model for ITEM evaluation
}

\author{
C.D. O'Mahony \\ Department of Computing and Technology \\ Australian Catholic University \\ e-mail:C.O'Mahony@castle.acu.edu.au
}

\begin{abstract}
How to determine the effectiveness of an organisation's information systems is the subject of continued debate in the IS community. Difficulties surround such issues as agreement on evaluation criteria, agreement on quantitative and qualitative methods, and the politicising of the evaluation process. In this paper, the author relates the nature of school information systems to mainstream information systems research. The literature surrounding Information Technology in Educational Management (ITEM) is reviewed, and an underlying model for school IS evaluation is presented. Using previous results as a basis, the author proposes a strategy for investigating the link between a school's culture and its IS emphases.
\end{abstract}

\section{Keywords}

Educational management, administration, evaluation/formative, modelling

\section{INTRODUCTION}

Any discussion of Information Technology in Educational Management (ITEM) makes assumptions concerning broader concepts from the domain of educational administration and the domain of information systems. School effectiveness and school culture are two key concepts in the educational administration literature that require elaboration. This analysis will show that both concepts have important implications for ITEM.

'Effectiveness' refers to an organisation's ability to meet the various needs of its constituent groups. In terms of schools, these groups are perceived as Teachers, Administrators, Parents and Students (Friedman, 1994). Definitions of school effectiveness are often, however, subjective and lack clarity (Glatter, 1986). Turney et al (1992) identify three major viewpoints on school effectiveness. These are: effectiveness based on measurable student achievement outcomes; a humanist, ethnographic tradition 
of effectiveness in relationships; and organisational culture as a key determinant of effectiveness.

In the prevailing economic climate, demands for business-like efficiency in schools colour the debate on what constitutes school effectiveness. A number of educational researchers have compared school effectiveness factors with attributes of business excellence, in particular using studies published by Peters \& Waterman (1982). In these studies, good schools are characterised by factors similar to those that characterise successful companies. These factors emphasise the importance of "people within the organisation, their values, their relationships and their perceptions, rather than on the structure or the product in terms of measurable outcomes or dollars saved" (Turney et al, 1992). Culture or value-set is seen to determine organisational excellence.

'Culture' is a recurrent theme in educational administration and school effectiveness literature. Again, this is a concept that eludes clear definition. The tone or climate of a school is often obvious, but hard to define. Turney et al (1992) suggest that there may be an executive culture, several teacher cultures and numerous student cultures in a school. They note that articulation between these is needed in order to form an overall organisational culture. Again, this theme has its parallels in management literature (Handy \& Aitken, 1986; Dunphy \& Stace, 1992), and a growing recognition in IS research (Romm et al, 1991; Yetton \& Southon, 1994).

Key issues for research in ITEM, then, are the contribution of school information systems to overall school effectiveness, and the importance and impact of school culture on school information systems.

\section{AN EVOLVING MANAGEMENT SECTOR}

Empirical evidence is clear that schools are seeking to better manage their IS resource (Barta et al, 1995). Like many other organisations, schools have been keen to acquire and deploy new technologies as they develop. Attempts to categorise the development of ITEM have identified three distinct stages over the past twenty years (Visscher, 1991a; 1995). The first stage was internally driven, whereby enthusiastic teachers utilised their existing knowledge to provide local solutions in specific areas, such as timetabling (Smith \& Hartley, 1983; Goodsell, 1995). A further stage was characterised by the emergence of hardware and software suppliers, offering solutions which involved the school as a passive participant. Since the mid-1980s, the emphasis has moved towards more integrated school information systems. This third stage is characterised by larger centralised projects that have attempted to deliver a total school package. Examples include OASIS in NSW (Dale \& Habib, 1991), HKSAS in Hong Kong (Fung, 1991) and SIMS in England (Bird, 1991).

Visscher's stages have many parallels in mainstream IS. Evolutionary theories have abounded in the IS literature since 1974 (Gibson \& Nolan, 1974; Nolan, 1979). Although the Nolan model has received mixed support, a similar evolutionary framework was proposed by Hirschheim et al (1988). In this instance, the model comprised three IS management phases, being "Delivery", "Reorientation" and "Reorganisation". The evolution from one phase to another is described as a function of time and an increasing education level among IS staff. Each phase is characterised by different priorities, management postures and business focus.

The author's work over the past two years has concentrated on collection of data from schools in England and Australia concerning existing IS management methods, and the development of techniques for school IS evaluation. One recurring problem noted by the author has been that purchases and implementations of IT have often been uncontrolled in schools, leading to technical incompatibilities and staff resentment (O'Mahony \& Dampney, 1995). Like Visscher, the author has noted a trend towards more sophistication in ITEM. Among independent schools, for instance, a trend towards the 
employment of professional IS managers was clear (O'Mahony, 1995). Between 1990 and 1995, the number of IS managers had grown from 13 persent to 65 percent in the schools studied.

Another critical insight was the influence of a school's culture on its information systems resource. In particular, this was made manifest through different religious denominations. Using the author's evaluation instrument, Catholic schools rated their information systems as less successful than their non-Catholic counterparts. Individual differences between school cultures are easily perceived. Myths and shared values are made manifest through such devices as mottos and mission or vision statements. What is not easy to perceive is why and how culture influences school IS management. The reasons for this influence lie in the area of organisational culture, and beg further investigation.

\section{PERSPECTIVES ON IS EVALUATION}

As schools make greater investments in their IS/IT portfolios, the evaluation of ITEM is becoming a major concern. The literature in educational administration and educational computing has little to offer in terms of evaluation tools (Telem, 1993). Visscher's review of approaches to computer assisted school administration led to the conclusion that "None of the countries has studied in a systematic way the quality of the available information systems. This is a universal problem; in fact, very little empirical data on system quality are available. ... This is regrettable since insight into variables that determine system quality can help to create better systems." (Visscher, 1991b)

The literature in IS research and practice is no closer in offering a solution. Hirschheim \& Smithson (1987) noted that "Although the information systems literature appears to be in widespread agreement regarding the need to evaluate the product and process of system development, the vehicle for undertaking such an evaluation is far from clear." More contemporary writers demonstrate that the area of IS evaluation is the subject of healthy debate. Bunker et al (1991) noted that "Definitions of the measurement of IS success in organisations is still the subject of fierce debate." Similarly Fitzgerald (1991) pointed out that "A review of relevant literature shows that ... very little research into ways of measuring the effectiveness of information systems strategic planning (ISSP) is reported."

Methods for IS evaluation fall on a broad spectrum from hard, quantitative techniques to soft, qualitative techniques. Quantitative approaches include measurement of IS in terms of return on investment (Weill, 1991; Willcocks, 1994). Work by DeLone \& McLean (1992) suggests on the other hand that IS success is much more difficult to quantify. Hirschheim \& Smithson (1987) assert that a pragmatic approach to IS evaluation is important. They point out that, although evaluation instruments should indeed be valid and reliable, they should also have practical application, and should provide a means for genuine information systems improvement. Practicality, they declare, is more important than theoretical elegance. In addition to methodological concerns, they and other researchers have noted that in many cases the evaluation exercise becomes a political exercise, thus sabotaging any potential benefits to be gained (Sauer, 1993).

The thriving debate on IS evaluation agrees with research in educational administration at least in this respect - that "effectiveness is one of the most pervasive yet least delineated organisational constructs relevant to all participants in organisational life" (Goodman \& Pennings, 1977). In DeLone \& McLean's terms, the dependent variable remains elusive. 


\section{AN UNDERLYING MODEL}

Friedman (1994) has suggested that school information systems can strategically affect four key groups. These groups are Administrators, Teachers, Students and Parents. Such ITEM activities as student registration, fees collection, assessment reporting and timetabling require the participation of at least some of these four groups. The use of IT to facilitate these activities requires appropriate consideration of multiple constituent needs. Effective school IS must meet the requirements of all four groups.. Using this insight as a basis, the author proposes the PACT (Parents, Administrators, Children and Teachers) construct as an overall model for school effectiveness (Figure 1).

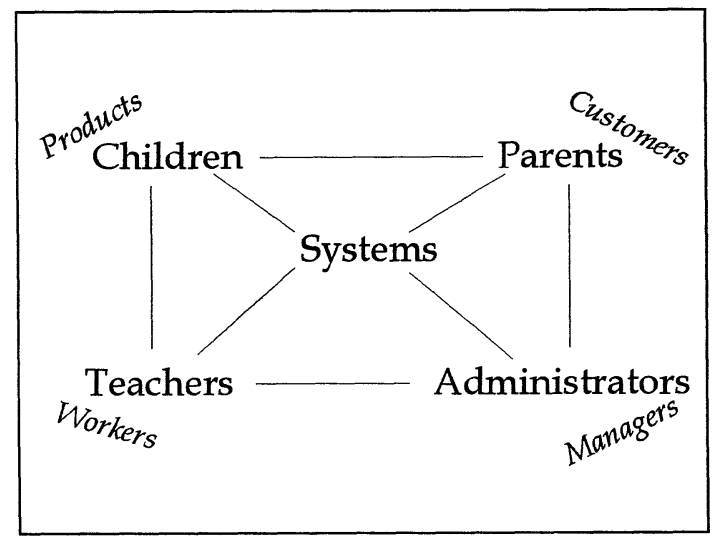

Figure 1 O’Mahony's PACT Model.

The PACT model highlights a number of relationships and dynamics within a school. The teaching/learning relationship, for instance, is readily recognised in the model, which encompasses both curriculum and administrative IT. Teachers and children make use of a variety of educational technologies to enhance the learning experience. Relationships between administrators and the other school groups are supported by a wide range of information systems. Management reporting systems, timetable generators and payroll packages all support information flow between administrators and teachers. Parents interact with the school through such functions as assessment reporting, pupil registration and invoicing, all of which can be supported by ITEM.

In a very real sense, the PACT model describes the communication of information throughout a school. This conforms with the body of opinion that positions information flow within the organisational communications domain (Bordow \& More, 1991; McGrath et al, 1995). As seen in Figure 1, the PACT model can be easily generalised to represent other organisations, whereby the Administrators represent Managers, Teachers represent Workers, Parents represent Customers, and Children represent Products.

As in other organisations, interactions between different constituent groups in schools can be fraught with problems. In particular, they are prone to the classic clash between practitioners and bureaucrats. This clash has been conclusively argued in work by Yetton \& Southon (1994). Using Scott-Morton's MIT'90s framework, Yetton \& Southon (1994) described IS dissatisfaction in terms of conflicts between hospital clinicians and hospital administrators. In the extreme, these two groups may be opposed in their strategy, structure, processes and technology.

The case for schools is much the same, with conflicts between teachers and administrators being identified in previous work by the author (O'Mahony, 1995). The PACT model can thus be viewed in dichotomy, with teachers and children in the 
qualitative, pastoral, effective camp, and administrators and parents in the quantitative, pragmatic, efficient camp of the school. In reality, the school community is not so clearly polarised, but an imbalance between these two viewpoints can lead to a mismatch in school IS management.

Enid Mumford has highlighted the need for an integrated approach to IS management. She states "one of the most important principles of socio-technical design ... that if a technical system is created at the expense of a social system, the results obtained will be sub-optimal." (Mumford, 1994). This principle translates well to the PACT model: school information systems which do not support all four (PACT) groups adequately are sub-optimal. In schools, the optimal balance must be found between the quantitative and qualitative dichotomy, between efficiency and effectiveness, between "PA" and "CT".

The author has referred previously to the notion of organisational culture as a key determinant of effectiveness (Turney et al, 1992). Recent IS research also supports this claim (Romm et al, 1991; Galliers \& Baker, 1995). The PACT model suggests that a school's culture is a function of the four key groups: Parents, Administrators, Children and Teachers. Differing cultures influence the design, development and deployment of school IS. The 'Optimisation Framework' (Figure 2) represents the dynamics of differing school cultures on information systems emphases. In this figure, the "PA" groups are shown on the "Administration IT" axis, and the "CT" groups are shown on the "Curriculum IT" axis.

Contrary to Yetton \& Southon (1994), it is the author's contention that efficiency and effectiveness are not diametrically opposed. Rather than being at opposing poles of the same axis, they in fact represent two orthogonal axes. Thus the key to optimising IS in schools is in balancing the cultural dynamics between Parent/Administrator ('efficient') groups and Child/Teacher ('effective') groups. The ideal situation for a school is represented in the top right quadrant, where group satisfaction for both curriculum and administrative IT is high. In this case, ITEM is optimal, being both effective and efficient.

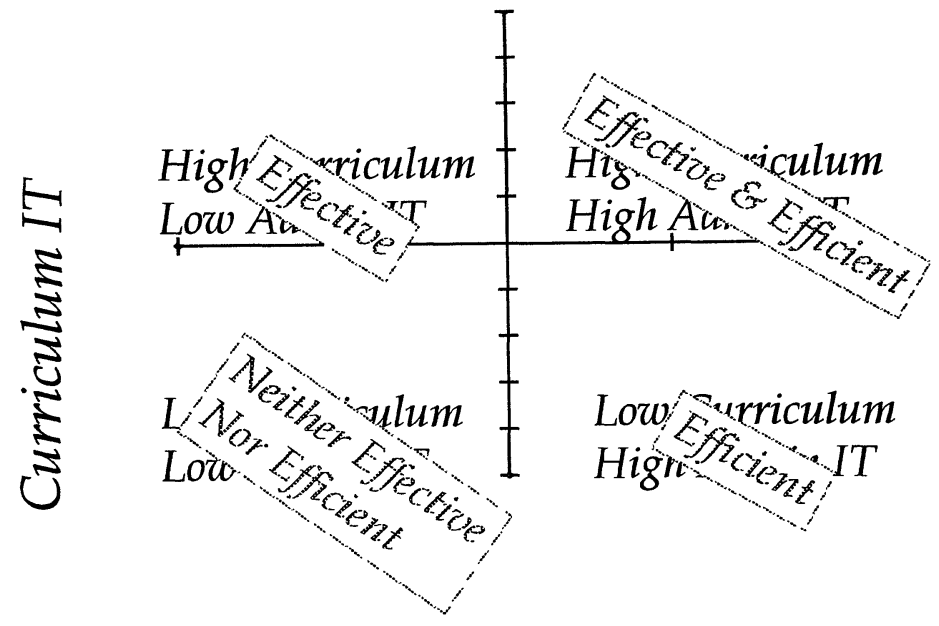

\section{Administration IT}

Figure 2 Optimising school information system. 
Initial support for this framework has already been achieved through case studies conducted by the author in England and Australia during 1994/5. These case studies have identified different organisational cultures prevalent in schools, and positioned their IS emphases accordingly on the author's optimisation grid. In both England and Australia, comparisons were made between State-run schools and independent schools with different religious affiliations. The general evolutionary trend is from the bottom left quadrant to the top right quadrant. Complete balance between the two axes was rare, however, with schools distributed towards either the effective or efficient quadrants. Details of these preliminary case studies are available from the author.

\section{APPLYING THE PACT MODEL}

The author's PACT model is currently undergoing further validation through a large research project involving both NSW State schools and Catholic Systemic schools. The first phase of the project involves a survey of 120 schools. The survey instrument comprises a six page questionnaire, developed from the author's previous pilot studies, and in collaboration with experts from both the information systems and educational administration domains. After mapping results to the author's Optimisation Framework, the second phase will involve in-depth case studies of specific school archetypes.

It is anticipated that results from the research project will relate closely to conclusions and implications in the existing IS and ITEM literature. Firstly, it is expected that survey responses will demonstrate evolutionary trends among schools using ITEM. Evolutionary models have abounded in IS literature since Nolan (Gibson \& Nolan, 1974; Nolan, 1979). Other examples of evolutionary models include Hirschheim et al (1988) and Visscher (1991a). Although the validity and generalisability of evolutionary models is often criticised in the literature, they persist and enjoy ongoing popularity.

Secondly, it is expected that results of the case study phase will support the growing awareness that organisational culture is an independent variable which is crucial to IS optimality. This recognition has arisen from practical research in public hospital systems (Yetton \& Southon, 1994) and tertiary educational institutions (Jordan, 1994), and theoretical work by DeLone \& McLean (1992).

The implications of the author's PACT model have a strong bearing on planning for schools of the future. From a reactive standpoint, ITEM developers need to consider carefully the impact of organisational culture on IS/IT developments. Conversely, ITEM developers need to consider carefully the impact of their developments on existing organisational culture. From a proactive standpoint, ITEM development can be used as an agent of change, enabling schools to progress from a position of low optimality to a position of high optimality, achieving both efficiency and effectiveness in their ITEM infrastructure. In a global climate of economic rationalism which seeks to do more with less, such strategies are particularly pertinent.

\section{CONCLUSION}

The evaluation of information systems in small organisations is an area of research that is still 'pre-scientific' (McGrath et al, 1995). This paper has discussed school IS evaluation in the broader context of IS research. Key issues identified are the importance of organisational culture to IS evaluations, and the inadequacy of quantitative models in assessing IS optimality.

To this end, the author has proposed the PACT model which describes the influence of constituent groups on school information systems, and an Optimisation Framework which enables analysis of the link between differing school cultures and their relative IS emphases, and particularly promotes a balance between efficiency and effectiveness 
cultures. The framework has already received anecdotal support, which the author aims to verify through further survey and case studies.

In this way, it is intended to expand our understanding of the principles which direct effective management of information systems in schools, which will lead to improved design, development and deployment of ITEM in the future.

\section{REFERENCES}

Barta, B.Z., Telem, M. and Gev, Y. (Eds) (1995) Information technology in educational management. Chapman \& Hall, London.

Bird, P. (1991) Computer assisted school administration in England. Journal of Research in Computing in Education, 24(1), 20-40.

Bordow, A., and More, E. (1991) Managing organisational communication. Longman, Sydney.

Bunker, D.J., Dean, R.G., Edmundson, R.H. (1991) The management of the information systems function. ISOP 1991, Wollongong, 161-181.

Dale, D., and Habib, A (1991) Administrative computing in the Australian educational system. Journal of Research on Computing in Education, 24(1), 120-145.

DeLone, W.H., and McLean, E.R. (1992) Information systems success: the quest for the dependent variable. Information Systems Research, 3(1), 60-95.

Dunphy, D. and Stace D. (1992) Under new management: Australian organisations in transition. McGraw-Hill, Sydney.

Fitzgerald, E. (1991) Effectiveness measures for IS strategic planning. ISOP, Wollongong, 387-404.

Friedman, E.A. (1994) A management perspective on effective technology integration: top ten questions for school administrators. T H E Journal, 22(4), 89-90.

Fung, A.C.W. (1991) Computer assisted school administration in Hong Kong. Journal of Research on Computing in Education, 24(1), 41-61.

Galliers, R.D. and Baker, B.S.H. (1995) An approach to business process reengineering: the contribution of socio-technical and soft OR concepts. INFOR, 33(4), 263-278.

Gibson, C. and Nolan, R.L. (1974) Managing the four stages of EDP growth. Harvard Business Review, 52(1), 76-88.

Glatter, R. (1986) The management of school improvement, in Understanding school management, Open University Press, Milton Keynes.

Goodman, P.S. and Pennings, J.M. (1977) New perspectives on organisational effectiveness. Jossey-Bass, san Francisco.

Goodsell, R. (1995) An investigation into timetabling in schools. Unpublished M. Comp. thesis, Macquarie University, Australia.

Handy, C. and Aitken, R. (1986) Understanding schools as organisations. Penguin, Harmondsworth.

Hirschheim, R., Earl, M., Feeny, D. and Lockett, M. (1988) An exploration into the management of the information systems function: key issues and an evolutionary model, in Proceedings on the Joint International Symposium on Information Systems, Sydney.

Hirschheim, R. and Smithson, S. (1987) Information systems evaluation: myth and reality, in Information analysis: selected readings (ed. R.D. Galliers), AddisonWesley, Wokingham, UK.

Jordan, E. (1994) Information strategy and organisation structure. Information Systems Journal, 4, 253-270.

McGrath, G.M., Dampney, C.N.G. and More, E. (1995) MP/L1: an automated model of organisational power and its application as a conflict prediction aid in information 
systems strategy implementation, in The 11th conference on artificial intelligence for applications. IEEE Computer Society Press, California, 56-64.

Mumford, E. (1994) New treatments or old remedies: is business process re-engineering really socio-technical design?. Journal of Strategic Information Systems, 3(4).

Nolan, R.L. (1979) Managing the crises in data processing. Harvard Business Review, 57(2), 115-126.

O'Mahony, C.D. (1995) Improving school information systems management: the quest for quality. Australian Catholic University, Sydney.

O'Mahony, C.D. and Dampney, C.N.G. (1995) Trends in the management of school information systems, in Proceedings: 6th Australasian Conference on Information Systems. Curtin University, Perth, WA, 613-631.

Peters, T.J. and Waterman, R.H. (1982) In search of excellence: lessons from America's best-run companies. Harper \& Row, New York.

Romm, T., Pliskin, N. and Weber, Y. (1991) Identifying organisational culture clash in MIS implementations: when is it worth the effort?. Information Management, 21(2), 99-109.

Sauer, C. (1993) Why information systems fail: a case study approach. Alfred Waller, Henley-on-Thames.

Smith, J. and Hartley, B. (1983) Microcomputers for school management. Nepean C.A.E., Sydney.

Telem, M. (1993) Information technology: a missing link in educational research. Journal of Research on Computing in Education, 26(1), 123-142.

Turney, C., Hatton, N., Laws, K., Sinclair, K. and Smith, D. (1992) The school manager. Allen and Unwin, North Sydney.

Visscher, A.J. (1991a) School administrative computing: a framework for analysis. Journal of Research on Computing in Education, 24(1), 1-19.

Visscher, A.J. (1991b) Computer assisted school administration and management: the state of the art in seven nations. Journal of Research on Computing in Education, 24(1), 146-167.

Visscher, A.J. (1995) A fundamental methodology for designing management information systems for schools. Journal of Research on Computing in Education, 28(1), 231-249.

Weill, P. (1991) The information technology payoff: implications for investment appraisal. Australian Accounting Review, 1(1), 2-11.

Willcocks, L. (1994) Information management: the evaluation of information systems investments. Chapman and Hall, London.

Yetton, P. and Southon, G. (1994) The impact of strategic conflict on Information technology: a case study of a public teaching hospital. Australian Graduate School of Management, Kensington, NSW.

\section{BIOGRAPHY}

Christopher O'Mahony is an Associate Lecturer in the Department of Computing and Technology at the Australian Catholic University. As well as holding academic qualifications in Information Systems, he has many years experience in business, particularly the finance industry. He has a growing reputation in the use of qualitative methods for information systems research. Results of his research have been presented at the Fourth and Fifth Australasian Conferences on Information Systems, and at the Second European Conference on IT Evaluation. 